University of Nebraska - Lincoln

DigitalCommons@University of Nebraska - Lincoln

1996

\title{
Speciation of Uranium in Fernald Soils by Molecular Spectroscopic Methods: Characterization of Untreated Soils
}

\author{
David E. Morris \\ Patrick G. Allen \\ Materials Science and Technology Division \\ John M. Berg \\ Nuclear Materials Technology Division \\ Catherine J. Chisholm-Brause \\ Chemical Science and Technology Division \\ Steven Conradson \\ Materials Science and Technology Division \\ See next page for additional authors
}

Chemical Science and Technology Division, demorris@lanl.gov

Follow this and additional works at: https://digitalcommons.unl.edu/usdoepub

Part of the Bioresource and Agricultural Engineering Commons

Morris, David E.; Allen, Patrick G.; Berg, John M.; Chisholm-Brause, Catherine J.; Conradson, Steven; Donohoe, Robert; Hess, Nancy; Musgrave, John; and Tait, C. Drew, "Speciation of Uranium in Fernald Soils by Molecular Spectroscopic Methods: Characterization of Untreated Soils" (1996). US Department of Energy Publications. 215.

https://digitalcommons.unl.edu/usdoepub/215

This Article is brought to you for free and open access by the U.S. Department of Energy at DigitalCommons@University of Nebraska - Lincoln. It has been accepted for inclusion in US Department of Energy Publications by an authorized administrator of DigitalCommons@University of Nebraska - Lincoln. 


\section{Authors}

David E. Morris, Patrick G. Allen, John M. Berg, Catherine J. Chisholm-Brause, Steven Conradson, Robert Donohoe, Nancy Hess, John Musgrave, and C. Drew Tait 


\section{Speciation of Uranium in Fernald Soils by Molecular Spectroscopic Methods: Characterization of Untreated Soils}

DAVID E. MORRIS, *, †

PATRICK G. ALLEN, CATHERINE J. CHISHOLM - BRAUSE,,,$\perp$ STEVEN D. CONRADSON, ROBERT J. DONOHOE, ${ }^{\dagger}$

NANCY J. HESS,,$\triangle$

JOHN A. MUSGRAVE, ${ }^{\dagger}$ AND

C. DREW TAIT ${ }^{\dagger}$

Chemical Science and Technology Division, Materials Science and Technology Division, and Nuclear Materials Technology Division, Los Alamos National Laboratory, Los Alamos, New Mexico 87545

A combination of X-ray absorption, optical luminescence, and Raman vibrational spectroscopies along with ancillary techniques such as energy dispersive scanning electron microscopy and powder X-ray diffraction have been used to determine the chemical form of uranium in contaminated soils from the United States Department of Energy's (DOE) former uranium production facility located at Fernald, $\mathrm{OH}(30 \mathrm{~km} \mathrm{NW}$ of Cincinnati). The analyses described here have been carried out on soil samples prior to the applic ation of various decontamination technologies under development within the DOE's Uranium in Soils Integrated Demonstration Project. X-ray absorption studies have shown that $\sim 75-95 \%$ of the uranium in bulk samples from the site are in the hexavalent oxidation state. Because of the variety of source terms having several initial oxidation states, this consistency in oxidation state indicates that weathering has had an important role in determining the chemical form of the uranium in the soil. The application of complementary spectroscopic techniques has enabled us to identify specific chemical forms of much of this uranium, namely, autunite-like and schoepite-like phases. Additional uranium minerals were also noted, and their photodecomposition and spatial correlation with source term suggest that they may be uranium species complexed by photochemically degradable organic ligands.

\section{Introduction}

The Fernald Environmental Restoration Management Company, formerly known as theFeed Material Production
Center, is a United States Department of Energy (DOE) facility that historically served as one of the principal processing centersfor uranium. Processingoperationswere suspended in 1986, and the site is presently undergoing remediation of uranium and other radioactive and toxic wastes. In 1991 theFernald sitewas chosen by DOE's Office of Technology Development to serve as the host for the Uranium in Soils Integrated Demonstration (USID). Many different processes were employed at the Fernald site, and there are many different source terms for uranium in the soils $(1,2)$. The shallow subsurface $(\leqslant 1 \mathrm{~m})$ requires significant remediation to bring the site into compliance with anticipated regulatory standards.

A key factor in the successful and timely remediation of this and other contaminated sites is the availability of speciation information (i.e., specification of the oxidation state, the chemical form, and the physical state [surface precipitate, secondary mineral, or adsorbate]) on the contaminants, as the response of the contaminants to remediation technologies will vary as the speciation varies. This will especially be true when the contaminants (e.g., actinides) can exist in several different oxidation states in the environment. Once the speciation has been characterized, the remediation technology can be devised with the specific chemical and physical form of the contaminant in mind. This will lead to more efficient and less drastic remediation measures and enhance the possibility of retaining a viablesoil substrate. Speciation determinations can also serve a useful followup function because they can provide additional information on contaminated soils following the application of treatment technologies, including a valid assessment of the long-term stability of the contaminant. This information will be important to guide the remediation effort and to determine whether the contaminant site is stabilized with respect to migration and subsequent groundwater or aquifer contamination.

To adequately specify contaminant speciation, techniques that probe the structure at the molecular level are required. Elemental specificity (e.g., as provided by inductively-coupled plasma atomic emission or X-ray fluorescence spectroscopies), while important, is insufficient by itself. Techniques are also needed that are applicable to opaquesamples such as solids (e.g., soils and mineral assemblages) because these possess challenging optical properties. Two general approaches are possible that satisfy these criteria. The first is based on molecular spectroscopic methods that probe the vibrational and electronic properties of the system. This is the approach used by Los Alamos and described in this report. The second approach is based on analytical microscopies as

* Corresponding author telephone: 505-665-6487; fax: 505-6670851; e-mail address: demorris@anl.gov.

+ Chemical Science and Technology Division.

₹ Materials Science and Technology Division.

" Present address: Chemical Sciences Division, LawrenceBerkeley National Laboratory, Berkeley, CA.

$\S$ Nuclear Materials Technology Division.

${ }^{\perp}$ Present address: School of Marine Science, Virginia Institute of Marine Science, College of William and Mary, Gloucester Point, VA.

$\triangle$ Present address: BattellePacific Northwest National Laboratory, Richland, WA. 
TABLE 1

\section{Descriptions and Designations of Characterization Samples from the Production Area of the Fernald Plant}

source-term category

aqueous uranium waste aqueous uranium waste solid uranium product spills

airborne uranium release contamination

uranyl nitrate feed stock for PUREX process ${ }^{c}$

discarded solutions and runoff from decontamination activities

(1) shipping, receiving, and storing uranium; (2) sampling and analysis of incoming material; (3) processing residue storage incineration of uranium-contaminated combustible material designators ${ }^{a}$

characteristics ${ }^{b}$

$\begin{array}{ll}\text { SP2 } & \text { cores } \\ \text { SP8 } & \text { cores } \\ \text { SP4 } & \text { cores } \\ \text { B16, B24 } & \text { blends } \\ \text { SP9 } & \text { cores } \\ \text { A11, A14 } & \text { blends }\end{array}$

${ }^{a}$ We have opted to retain the same sample designations in this paper as have been used throughout the course of the USID to facilitate comparisons of results presented here with other project documentation and literature. ${ }^{b}$ For all samples listed here except SP8, both bulk samples and size/density fractionated samples were available for characterization. c For a description of the PUREX process, see Schulz, W. W.; Navratil, J . D.; Talbot, A. E., Eds. Science and Technology of Tributyl Phosphate, Volumes 1-3; CRC Press: Columbus, OH, 1984.

practiced for the USID by Buck and co-workers at Argonne National Laboratory (3).

For uranium speciation in Fernald soils, we have relied on three spectroscopic methods: X-ray absorption spectroscopy (XAS), optical luminescence spectroscopy, and Raman vibrational spectroscopy. XAS (4-7) provides oxidation-stateinformation [e.g., theratio of U(IV) to U(VI)] directly. It also determines the average local coordination environment about the target ion. Thus, the identity and number of coordinating atoms from ligandsand/ or surfaces and their bond lengths can be quantified. Optical luminescence spectroscopy is a very valuable probe for the speciation of hexavalent uranium moieties (i.e., $\mathrm{UO}_{2}{ }^{2+}$ species) (7-10). This method has excellent sensitivity, and because of the often distinct, species-specific nature of the hexavalent uranium emission spectrum, the method can beused as a "fingerprint" for speciation. Raman vibrational spectroscopy provides molecular structure information explicitly via the number, energy, and intensity of the observed vibrational transitions (11). This method can also be used as a fingerprint for species identification because of the distinctive nature of the Raman spectrum.

A number of experimental advantages can be identified that are specifically associated with these molecular spectroscopic probes for uranium speciation in soils: no invasive sample preparation is required, spatial ranges from greater than $1 \mathrm{~cm}^{2}$ to less than $100 \mu \mathrm{m}^{2}$ can be probed by changing the degree of focus of the excitation source, and all of these spectroscopic probes work equally well with amorphous samples and/ or submonolayer coatings (specimens for which diffraction-based methods fail). For example, wehave investigated thespeciation of uranyl ions as submonolayer edge-site and exchange-site sorption complexes on layered clay minerals $(7,9,10)$. Finally, all of these methods can be implemented in a temporallyresolved mode by using pulsed excitation and/or gated detection. This enables better distinction between various uranium species and against signal from background (i.e., naturally-occurring) constituents.

In this paper, we present speciation characterization data on the uranium contamination found in shallow subsurface soils from a number of sites at the Fernald production facility. TheX-ray absorption spectroscopy data provide definitive evidence that the bulk oxidation-state distribution of uranium favors hexavalent species. These bulk oxidation-state data are the key baseline information for devising remediation strategies. More precise hexavalent uranium species identifications were made possible through luminescence and Raman spectroscopy data, and data from both techniques were required to confirm assignments for the dominate class of hexavalent species. In a companion paper (12), we will report characterization data on these same soils after they have undergone treatment by one of several methods under development within the USID for the removal of uranium.

\section{Experimental Section}

Samples. Sampling efforts at the plant in support of the USID focused on three generic types of uranium source terms: (1) aqueous uranium wastes, (2) solid uranium products released through spills, and (3) airborne uranium waste released as dust and aerosols $(2,13)$. This paper is concerned with samples obtained from four sites at the main production area of the Fernald plant that encompass these three generic source terms. Table 1 summarizes the sites, the source term(s), and the types of samples (e.g., cores vs homogenized blends).

The initial characterization efforts focused on 2-in. diameter core samples for which no size and/or density fractionation was carried out. These samples were, however, sectioned into vertical segments (2) as described below. Following the initial characterization work, soils from two sites wereselected for detailed remediation studies. These sites were the Incinerator Area and the Plant 1/Storage Pad Area. Additional large-scale soil samples from these sites were collected and homogenized by blending (14) for remediation treatability studies. Subsamples from these homogenized lots were taken for the characterization work reported here. Finally, to test the ability to selectively concentrate uranium species in soil fractions, portions of the original core samples and the homogenized samples were subjected to size and density fractionation at Oak Ridge National Laboratory (ORNL) (15). The bulk uranium concentration in all samples was determined in S. Y. Lee's laboratories at Oak Ridge using neutron activation analysis and/or $\gamma$-spectroscopy. Additional details and specific results not cited here can be found in refs 2,13 , and 15 .

We obtained specimens from the library of uraniumbearing minerals maintained by the University of New Mexico, from the Smithsonian Institution collection, and from the inventory of solid uranium phases maintained at Los Alamos. We also procured some specimens (mostly silicate phases) from the Mineralogical Research Company in San Jose, CA. These samples were used to develop the spectral database of uranyl luminescence and Raman data to aid in identifying uranyl species found in the Fernald soils and to construct the X-ray absorption spectroscopy oxidation-state calibration plot described in detail below.

Instrumentation and Analysis. Luminescence and Raman data were collected on a SPEX Industries Model 
1403 double monochromator using an argon-ion laser source, a luminescence-adapted microscope system assembled at Los Alamos and described in detail elsewhere (16), or a SPEX Industries Fluorolog equipped with a phosphorimetry accessory. In all cases, the emitted or Raman scattered light was detected using a photomultiplier tube. X-ray powder diffraction patterns were collected on a Phillips Model XRG 3100 computer-controlled X-ray diffractometer using $\mathrm{Cu} \mathrm{K}_{\alpha}$ radiation. Data points were collected at 0.02 steps/ deg $2 \phi$ with an integration time of up to $150 \mathrm{~s} / \mathrm{step}$. The scanning electron microscopy data were collected on an International Scientific Instruments Model ISI-SX-40 unit interfaced to a Tracor Northern Pulse Processing and Detector Electronics package.

Uranium $L_{\text {III }}$ X-ray absorption spectral data were obtained at both the National Synchrotron Light Source(NSLS) at Brookhaven National Laboratory and the Stanford Synchrotron Radiation Laboratory (SSRL). All data were collected at ambient temperature and pressure using a 13element Ge detector. Energy calibrations were performed by periodically measuring the edge of a $\mathrm{U}_{0.98} \mathrm{~W}_{0.02}$ sample, the $L_{\text {III }}$ edge inflection point of which was defined as 17167 $\mathrm{eV}$. $\mathrm{E}_{0}$ was defined as $17185 \mathrm{eV}$. Spectra were normalized by setting the value of a polynomial fit through the preedge to zero and a polynomial fit through the post-edge to unity at $E_{0}$. EXAFS (extended X-ray absorption fine structure) was extracted as the difference between the data and a polynomial spline fit through the post-edge region, normalized by the elemental absorption falloff. Curve fitting phases and amplitudes were obtained both from the FEFF6 code (17) and from a spectrum of aqueous $\mathrm{UO}_{2}{ }^{2+}$ at $\mathrm{pH} 2$.

EXAFS does not provide explicit determinations of the structures of individual species in multicomponentsamples. Rather, EXAFS determines bulk structural features from which the structures of individual species are inferred. Because we do not know a priori what species are present in the samples, the analysis is performed, and the results are reported as if every uranium atom possessed the population weighted "average" structure. In the case of the samples from the Fernald site, the uranium is present predominantly as $\mathrm{U}(\mathrm{VI})$ and $\mathrm{U}(\mathrm{IV})$ as determined from XAS edge and near-edge features (see below). Most $\mathrm{U}(\mathrm{VI})$ species appear to be conventional -yl species $\left(\mathrm{UO}_{2}{ }^{2+}\right)$, possessing two axial doubly bound oxygen ligands with bond lengths of ca. $1.8 \AA$ and equatorial ligands with bond lengths of $2.3-2.5 \AA$. The U(IV) species do not have the -yl ligands, but their local structure is otherwise similar to that of the $\mathrm{U}(\mathrm{VI})$, with a first shell consisting of atoms that will be at the shorter end of the range found for the $U(\mathrm{VI})$ equatorial ligands. The curve fits of the EXAFS data are carried out under the assumption that all samples contain some fractional population of $\mathrm{U}(\mathrm{VI})$ species with the $-\mathrm{yl}$ oxygens constituting the nearest shell. In the case of $\mathrm{U}(\mathrm{VI})$ species, the next closest shell will be the equatorial shell. In the case of U(IV) species, this shell of atoms will be the innermost coordination shell. For simplicity in discussing these results, we refer to this shell as the "equatorial" shell for both the $\mathrm{U}(\mathrm{VI})$ and $\mathrm{U}(\mathrm{IV})$ species.

Calibration of Bulk Oxidation-State Determinations Using XAS. One of the most important pieces of information needed to make remediation decisions for contaminated soils is the distribution of oxidation states of the contaminant on the bulk sample scale. A number of X-ray absorption spectral signatures can be used to estimate the bulk oxidation-state distribution of uranium in soils (e.g., the position of the absorption edge in the spectrum and the amplitude of the near-edge feature that correlates with high hexavalent uranium concentrations). We were particularly motivated to find a rigorous calibration scheme that does not rely on precise energy calibration (as required when the absorption edge energy is used), because of the experimental difficulties associated with energy calibration and the inherent drift in this calibration over the course of an experimental run on dilute samples requiring substantial signal averaging.

To explorealternativecalibration possibilities, a suiteof synthetic oxidation-state mixtures was prepared from two oxidation-state pure end-members; meta-autunite [Ca$\left(\mathrm{UO}_{2}\right)_{2}\left(\mathrm{PO}_{4}\right)_{2} \cdot 2-6 \mathrm{H}_{2} \mathrm{O}$, Smithsonian Institution collection] as the hexavalent uranium end-member and uraninite [high-fired $\mathrm{UO}_{2}$, Los Alamos] as the tetravalent uranium end-member. These end-members were chosen because they were identified as significant constituents of the uranium contamination in the Fernald soils. Because of the variability in the number of waters of hydration in the meta-autunite sample, the mid-point value of 4 was assumed in making stoichiometric calculation for the samplemixtures. Samples containing mixtures of $\sim 25,50$, and $75 \%$ (wt/ wt) wereprepared, as were pureend-member samples.

The background-corrected XAS spectra are shown in Figure 1A. Several isosbestic points are apparent in these spectra, demonstrating that only two uranium species are contributing to the total spectral envelope, and their contributions are in accordance with the Beer-Lambert law for absorption (18). Thevalues of thespectral signatures (e.g., edge position, whitelineamplitude, etc.) were plotted versus the fractional composition of the samples to search for the best linear correlation. The best correlation was found for the position of the peak of the Gaussian function that defines the near-edgefeature (which is most prominent in samples of high $\mathrm{U}(\mathrm{VI})$ concentration) relative to the midpoint (inflection point) of the absorption edge. Data from the unconstrained mathematical fits of the spectra (illustrated for the $100 \% \mathrm{U}(\mathrm{VI})$ standard in Figure 1B) were used to generate the oxidation-state calibration curve (Figure2). From an analysis of XAS data from contaminated soil samples, the calibration curve in Figure 2 provides the bulk oxidation-state distribution valuewith good precision (19).

\section{Results and Discussion}

The following important baseline information on the Fernald site was taken from the report by Lee and Marsh (2). The background levels of uranium in uncontaminated reference topsoils taken in the vicinity of the production facility are typically $\sim 3-5 \mathrm{ppm}$. Uranium concentrations in the cores and homogenized blends from the production site (prior to size and density fractionation) range from $\sim 10$ to 8000 ppm, with an average value of $\sim 500 \mathrm{ppm}$. With few exceptions (e.g., SP2) only the top $0.25-0.3 \mathrm{~m}$ of the soil have been contaminated. The $\mathrm{pH}$ of the reference topsoil is in the 5.4-6.3 range, indicative of surface weathering of the underlying glacial till (2). In contrast, the $\mathrm{pH}$ of the cores and homogenized blends is in the range $\sim 7-8.5$, reflecting the large concentrations of calcite and dolomite (see below) and demonstrating that the surface soils within the production facility were significantly 

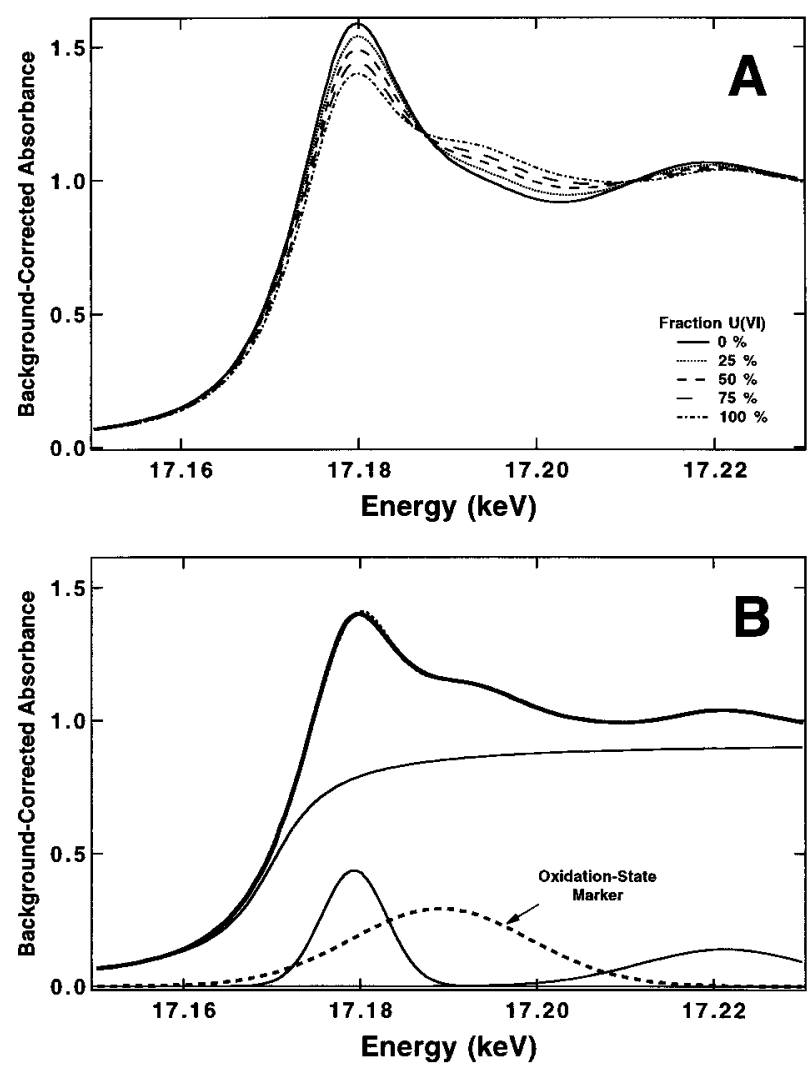

FIGURE 1. (A) Background-corrected uranium $L_{\text {III }} X$-ray absorption spectra for synthetic mixtures of oxidation-state pure uranium mineral end-members uraninite $\left(\mathrm{UO}_{2}\right.$, tetravalent) and meta-autunite (hexavalent, see Table 2). (B) Deconvolved components from the fit of the $X$-ray absorption spectra for $100 \% \mathrm{U}(\mathrm{VI})$. The bold solid line is the experimental spectrum, and the small dashed line is the unconstrained fit based on the summation of one arctangent and three Gaussian functions. The peak position of the long-dashed Gaussian component relative to the inflection point of the absorption edge (arctan function) is used for the oxidation-state determination.

disturbed by production activities. (For example, there is documented evidence of the use of limestoneas a filler and groundcover over much of the production site.)

$X$-ray diffraction (XRD) data have been collected by us and by other groups $(2,15)$ and are discussed briefly here as background material. Powder patterns of the untreated soils from the main production facility identified quartz, feldspars $(\mathrm{Ca}, \mathrm{Na}$, and $\mathrm{K})$, dolomite, and calcite as the principle minerals present, with quartz contributing the dominant pattern. Clay minerals (chlorite, illite, vermiculite, and kaolinite) while present were not important features, and XRD peaks associated with themica muscovite were observed. While apatite was not noted in our XRD scans, trace amounts have been reported from analytical electron microscopic (AEM) studies done elsewhere (3).

X-ray Absorption Data. X-ray absorption spectral data have been obtained for specimens from all the samples identified in Table 1. Typical spectra for bulk samplesfrom sample lots SP2, SP4, and SP9 are illustrated in Figure 3. These spectra are all very similar through the edge and near-edge regions, and they correlate extremely well with the spectra obtained for pure hexavalent uranium species such as meta-autunite (Figure 1A) or aqueous solutions of uranyl nitrate (not shown). This is prima facie evidence that the majority of the uranium exists in the hexavalent oxidation state. Quantitative data on the $\mathrm{U}(\mathrm{VI}): \mathrm{U}(\mathrm{IV})$ oxidation-statedistribution $(19,20)$ in the bulkcoresamples

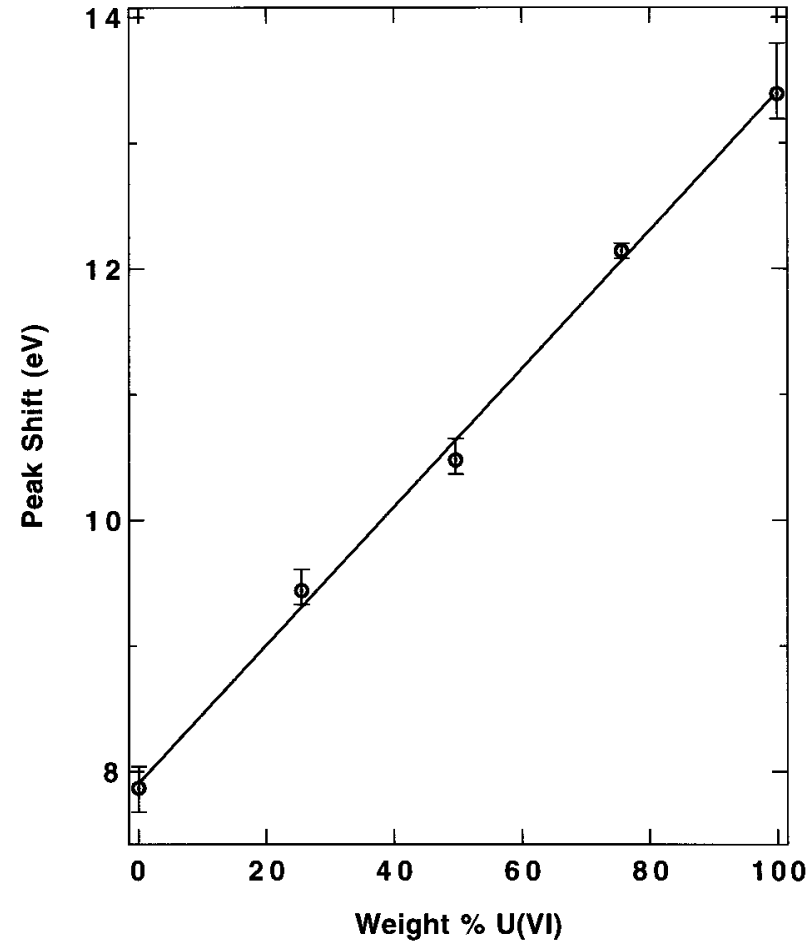

FIGURE 2. Calibration plot ( $R=0.9987)$ for determining the $U(V I)$ : $U(I V)$ oxidation-state distribution in Fernald soil samples based on the X-ray absorption data from Figure 1 . The error bars show $n$ for the values of the peak position are the range of values obtained for the peak position from five individual $X$-ray absorption scans.

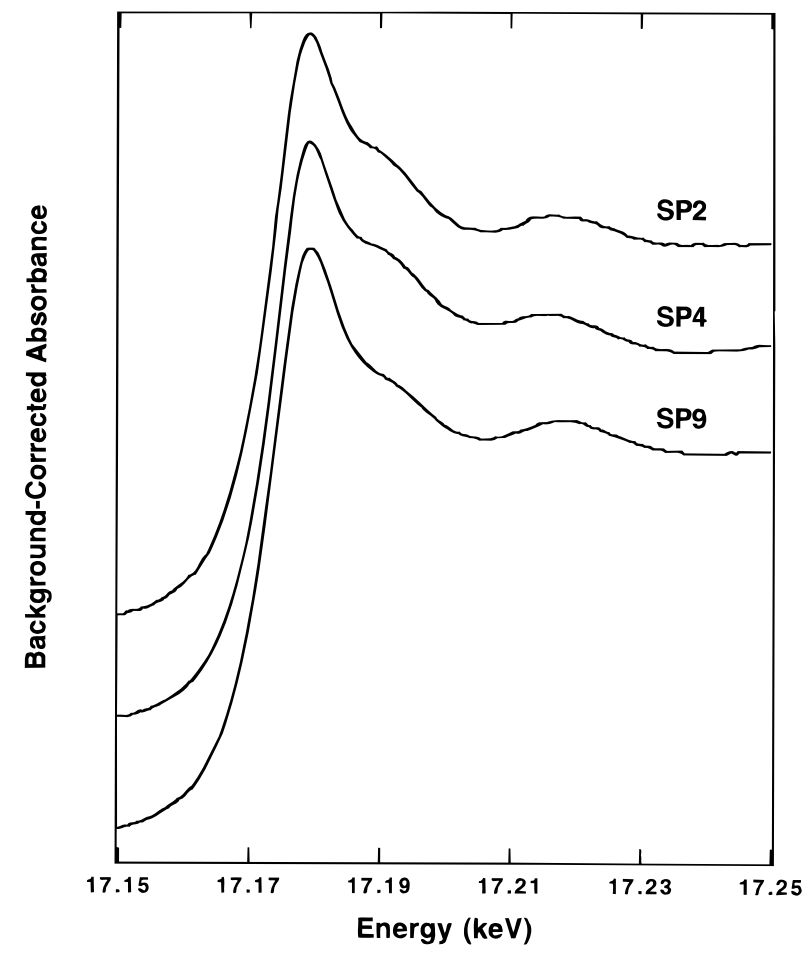

FIGURE 3. Background-corrected uranium $L_{\text {III }} X$-ray absorption spectra for uranium-c ontaminated Fernald soils from lots SP2 $(0.25-$ $0.5 \mathrm{~m}$ horizon), SP4, and SP9.

based on the calibration plot in Figure 2 areasfollows: SP2 is $95: 5$, SP4 is 75:25, SP8 is $85: 15$, and SP9 is 90:10. Similarly large abundances of $\mathrm{U}(\mathrm{VI})$ species to $\mathrm{U}(\mathrm{IV})$ species were found in the homogenized blends from thel ncinerator Area (A11 is 80:20 and A14 is 70:30) and the Plant 1/Storage Pad Area (B16 is 90:10 and B24 is 95:5). 


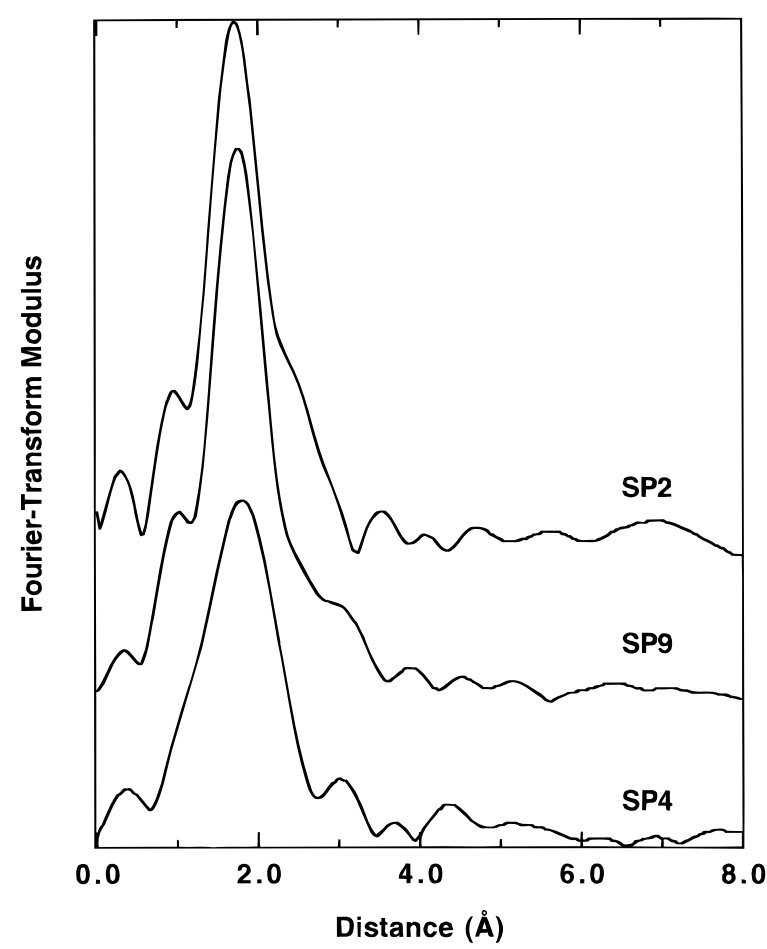

FIGURE 4. Fourier-transform representations of the EXAFS for uranium-contaminated Fernald soils from lots SP2 $(0.25-0.5 \mathrm{~m}$ horizon), SP4, and SP9. The contribution to the EXAFS from the axial oxygen (yl) atoms has been mathematically removed to facilitate comparison of the equatorial features.

Analyses of the EXAFS from the spectra shown in Figure 3 reveal the existence of $-y l$ oxygen atoms from the hexavalent uranium at $\sim 1.8 \AA$ and an equatorial shell of atoms with bond lengths in the range from $\sim 2.31$ to 2.36 $\AA$. By mathematically filtering the contribution to the EXAFS signal from the axial -yl atoms, it is possible to focus on the contribution to the EXAFS from theequatorial atoms (Figure 4). While these radial structure functions look comparablefor SP2 and SP9, thereis an obvious diminution in amplitude and increase in peak width in the radial structure function for SP4. This variation in the structure of the equatorial shell is significant and indicates that, although the uranium is present predominantly as a $\mathrm{UO}_{2}{ }^{2+}$ moiety in all samples, there are variations in the speciation of the uranium for different samples. As identified in the optical spectroscopic data described below, micron-sized autunite-like and schoepite-like phases are present in the samples. Becausestructures determined by EXAFS are the population-weighted averages of all of the uranium species present in the $\mathrm{mm}^{2}$ squared size X-ray beam, different relative amounts of these two phases could account for the sample to sample variation in the samples. Furthermore, the spectroscopic manifestations from schoepite need not be constant, as it changes crystal form as it ages (21). Alternatively, the phosphate phase could bea combination of autunite and phosphuranylite, with the relative percentages varying from site to site.

The X-ray absorption data for the soils that have undergone size and density fractionation reveal important trends in the partitioning of uranium species in the various fractions. As noted by Lee's group at ORNL (15), significant amounts of uranium are found in each fraction. Furthermore, density fractionation results in greater uranium concentrations in the heavier fractions for essentially all size fractions. Our results further show that these heavy density fractions al so have the greatest relative abundance of $U(I V)$ species to $U(V I)$ species seen thus far in our investigations. For example, for the sand size fraction [2- $-0.053 \mathrm{~mm}, 21 \%$ of the whole soil mass, and $48 \%$ of the total uranium (2)] of the SP9 core, the light density cut ( $\rho$ $<3.2 \mathrm{~g} / \mathrm{cm}^{3}$ ) has a $\mathrm{U}(\mathrm{VI}): \mathrm{U}(\mathrm{IV})$ ratio of $75: 25$ whereas the heavy density cut $\left(\rho>3.2 \mathrm{~g} / \mathrm{cm}^{3}\right)$ has a ratio of 55:45. Similarly, for the sand-size fraction of the All soil ( $10 \%$ of the whole soil mass and $25 \%$ of the total uranium), the $\mathrm{U}(\mathrm{VI}): \mathrm{U}(\mathrm{IV})$ ratio is $50: 50$ for the light density cut $(\rho<2.8$ $\left.\mathrm{g} / \mathrm{cm}^{3}\right), 30: 70$ for the medium density cut $(2.8<\rho<3.2$ $\left.\mathrm{g} / \mathrm{cm}^{3}\right)$, and $20: 80$ for the heavy density cut $\left(\rho>3.2 \mathrm{~g} / \mathrm{cm}^{3}\right)$. Some materials losses were noted in these size and density fractionations $(2,15)$, so mass balances are not exact.

The soil matrix is reported (15) to consist principally of quartz $\left(\rho=2.65 \mathrm{~g} / \mathrm{cm}^{3}\right)$, calcite $\left(\rho=2.71 \mathrm{~g} / \mathrm{cm}^{3}\right)$, dolomite $\left(\rho=2.85 \mathrm{~g} / \mathrm{cm}^{3}\right)$, and clay minerals, primarily illite $(\rho=$ $2.6-2.9 \mathrm{~g} / \mathrm{cm}^{3}$ ) and chlorite $\left(\rho=3.1-3.2 \mathrm{~g} / \mathrm{cm}^{3}\right.$ ). (All density values were taken from ref 22.) Thus, the density fractionation should concentrate most of the soil mass (quart, calcite, and dolomite) in the light fraction while concentrating the clay minerals in the heavy-density fraction. Essentially all uranium mineral phases identified in the Fernald soils have densities greater than the breakpoint used in the density fractionation (22). For example, the $\mathrm{U}(\mathrm{VI})$ phosphate minerals all have densities in the range of $3.5-4 \mathrm{~g} / \mathrm{cm}^{3}$. Uraninite $\left[\mathrm{UO}_{2}\right]$, a typical U(IV) species, hasa density of $7.5-10 \mathrm{~g} / \mathrm{cm}^{3}$. Thus, if theuranium-bearing phases exist only as particulates not physically or chemically associated with thesoil matrix, they should all beselectively concentrated in theheavy-density fraction. Since complete fractionation of all the uranium in the heavy-density cut is not observed, the uranium phases must be associated with the soil matrix components to give particulates having average densities lying between the values of theindividual soil matrix and uranium phase constituents.

Optical Spectroscopic and Microscopic Data. Due to the predominance of hexavalent uranium in the Fernald soils, optical spectroscopic methods and optical and electron microscopies were exploited to attempt a more definitive characterization of the uranium species. Luminescencefrom the uranyl moiety allowed visual inspection of the uranium contamination through an optical microscope. Most of the luminescent uranium was concentrated in platey, tabular grains ranging in size from 10 to $100 \mu \mathrm{m}$, as had been noted previously (2), although SP9 also showed finely dispersed emitting particles. Dispersed (i.e., nongranular) luminescence, as expected from uranyl surface and exchange complexes on clay minerals $(9,10)$ and metal oxides, was not observed. However, it should be noted that monolayer surface adsorption to iron oxyhydroxy phases in particular may lead to deactivation of luminescence through quenching. Many of the luminescing uranium grains were physically associated with goethite (in a multilayer to macroscopic manner that did not totally quench the luminescence), and some occurrence with quartz was also noted. All samples showed broad luminescence profiles in the blue that are attributed to organics in the soil and not to any uranium contamination. The samples from SP4 and SP8 contained only small amounts of green emittinguranium particles, whereas theSP2 sample and all samples from the Incinerator Area (SP9, All, and A14) contained numerous green emitting particles as well as orangeand red emitting particles (see below). This trend is consistent with the elemental analytical results which 


\begin{tabular}{|c|c|}
\hline $\begin{array}{l}\text { TABLE } 2 \\
\text { Chemical Formulas } \\
\text { Uranium(VI) Minera }\end{array}$ & r Potentially Relevant \\
\hline mineral & formula \\
\hline $\begin{array}{l}\text { Hydrox } \\
\text { becquerelite } \\
\text { billietite } \\
\text { curite } \\
\text { schoepite }^{d}\end{array}$ & $\begin{array}{l}\text { a and Oxyhydroxides } \\
\qquad \mathrm{Ca}\left[\left(\mathrm{UO}_{2}\right)_{6} \mathrm{O}_{4}(\mathrm{OH})_{6}\right] \cdot 8 \mathrm{H}_{2} \mathrm{O} \\
\mathrm{Ba}\left[\left(\mathrm{UO}_{2}\right)_{6} \mathrm{O}_{4}(\mathrm{OH})_{6}\right] \cdot 4 \mathrm{H}_{2} \mathrm{O} \\
\mathrm{Pb}_{2} \mathrm{U}_{5} \mathrm{O}_{17} \cdot 4 \mathrm{H}_{2} \mathrm{O}^{c} \\
\left(\mathrm{UO}_{2}\right)(\mathrm{OH})_{2} \cdot \mathrm{H}_{2} \mathrm{O}^{e}\end{array}$ \\
\hline $\begin{array}{l}\text { kamotoite } \\
\text { liebigite } \\
\text { rutherfordine }\end{array}$ & $\begin{array}{l}\text { Carbonates } \\
\qquad \begin{array}{l}\mathrm{Y}_{2} \mathrm{U}_{4}\left(\mathrm{CO}_{3}\right)_{3} \mathrm{O}_{12} \cdot 14.5 \mathrm{H}_{2} \mathrm{O} \\
\mathrm{Ca}_{2} \mathrm{UO}_{2}\left(\mathrm{CO}_{3}\right)_{3} \cdot 11 \mathrm{H}_{2} \mathrm{O} \\
\mathrm{UO}_{2} \mathrm{CO}_{3}\end{array}\end{array}$ \\
\hline $\begin{array}{l}\text { beta-uranophane } \\
\text { boltwoodite } \\
\text { cuprosklodowskite } \\
\text { kasolite } \\
\text { sklodowskite } \\
\text { soddyite }\end{array}$ & $\begin{array}{l}\text { Silicates } \\
\quad \mathrm{Ca}\left(\mathrm{UO}_{2}\right) \mathrm{SiO}_{3}(\mathrm{OH})_{2} \cdot 5 \mathrm{H}_{2} \mathrm{O}^{f} \\
\left(\mathrm{H}_{2} \mathrm{O}\right)_{\mathrm{K}}\left(\mathrm{UO}_{2}\right)(\mathrm{SiO}) \\
\left(\mathrm{H}_{3} \mathrm{O}\right)_{2} \mathrm{Cu}\left(\mathrm{UO}_{2}\right)_{2}\left(\mathrm{SiO}_{4}\right)_{2} \cdot 2 \mathrm{H}_{2} \mathrm{O}^{f} \\
\mathrm{~Pb}_{\left(\mathrm{UO}_{2}\right) \mathrm{SiO}_{4} \cdot \mathrm{H}_{2} \mathrm{O}} \\
\left(\mathrm{H}_{3} \mathrm{O}\right)_{2} \mathrm{Mg}\left(\mathrm{UO}_{2}\right)_{2}\left(\mathrm{SiO}_{4}\right)_{2} \cdot 2 \mathrm{H}_{2} \mathrm{O} \\
\quad\left(\mathrm{UO}_{2}\right)_{2} \mathrm{SiO}_{4} \cdot 2 \mathrm{H}_{2} \mathrm{O}\end{array}$ \\
\hline $\begin{array}{l}\text { meta-ankoleited }^{d} \\
\text { meta-autunite }^{d} \\
\text { meta-torbernite } \\
\text { phosphuranylite } \\
\text { saleeite }\end{array}$ & 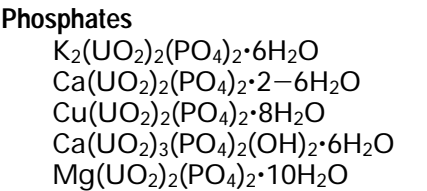 \\
\hline
\end{tabular}

a Data taken from refs 22 and 32. ${ }^{b}$ Unless indicated otherwise, both emission and Raman data have been collected and compared to data from uranium species in Fernald soils. ' Emission was totally quenched for this specimen. ${ }^{d}$ Data were collected on specimens from the Smithsonian Institute and the University of New Mexico. ${ }^{e}$ Alternate formulation for this mineral is $\mathrm{UO}_{3} \cdot 2 \mathrm{H}_{2} \mathrm{O}$, and many different hydration states are known (21). ${ }^{f}$ Emission data only were obtained for this specimen.

showed higher uranium contamination in bulk samples SP2, SP9, A11, and A14 (2, 15).

Under visual inspection, two types of hexavalent uranium emitters were classified: green emitters and orange/ red emitters. Energy dispersive SEM confirmed the presence of uranium in these emissive particles. SP2 contained large green and orange emitters, while SP9, A11, and A14 contained large green, finely dispersed green, and orange emitters. SP9also contained a small amount of red emitters. Because of the particulate nature of the uranium, it was possibleto manually sort the uranium contamination from bulk SP2 samples under UV illumination, thereby concentrating large green emitters and orange emitters separately. The XRD pattern from the green emitter sample contained small peaks consistent with the oxyhydroxide uranium mineral schoepite (chemical formulas for mineral names are given in Table 2). Energy dispersive SEM of the concentrated green emitters in SP2 showed both silicon and phosphorus as well as uranium, calcium, potassium, and magnesium. Therefore, additional uranyl mineral(s) with silicate and/or phosphorus ligands are possible. Furthermore, the platey crystal habit of the green emitters in theFernald soil is consistent with an oxyhydroxide (e.g., schoepite) and/or a phosphate phase (e.g., autunite), whereas silicates (e.g., sklodowskite) tend to have acicular crystal habits. Therefore, the observation of tabular grains argues against silicate minerals as a major phase, and the silicon found in the SEM may be from residual soil components such as quartz. The energy dispersive SEM for hand-concentrated orange emitters is much simpler than for the green emitters: silicon is reduced in importance, phosphorus is not present at all, and the cations $\mathrm{Mg}$ and $\mathrm{Ca}$ are almost absent. In fact, the only cations in

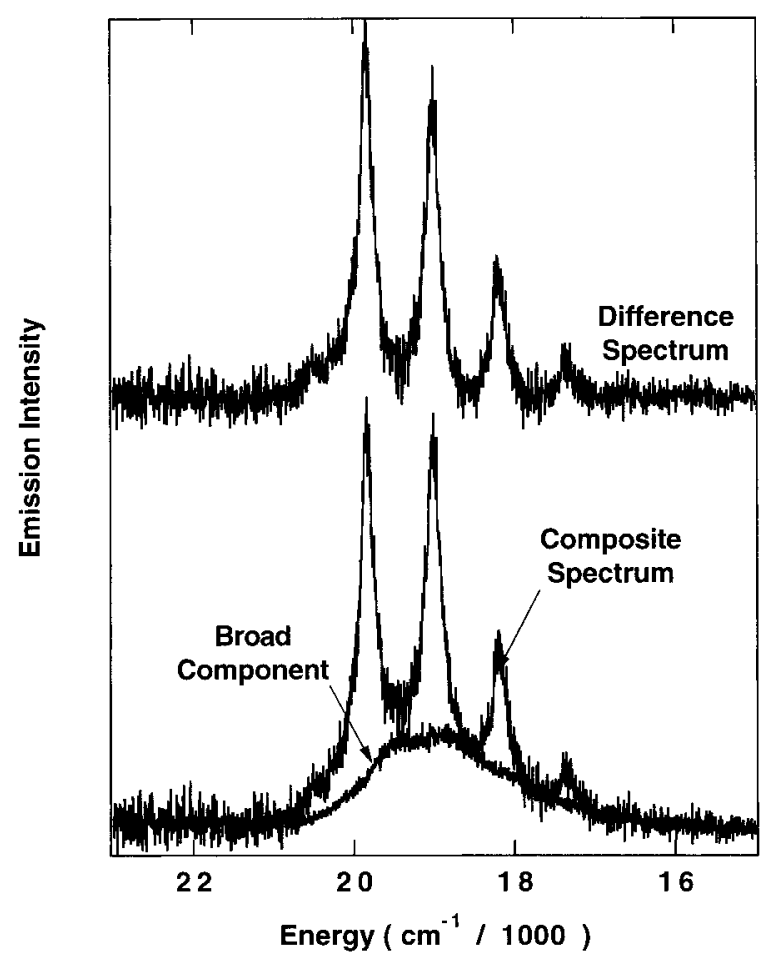

FIGURE 5. Luminescence spectra obtained from a bulk sample of lot SP2 using defoc used (i.e., $\sim 2 \mathrm{~mm}$ beam w aist) $364 \mathrm{~nm}$ excitation from an argon-ion laser. The composite spectrum consists of a broad, underlying spectrum and a narrow-band component show $n$ as the difference spectrum.

abundance are Kand Al, with trace Fealso present. Clearly the orange emitters present in the SP2 samples are not uranyl phosphates (including organophosphates), nor are they likely to beuranyl silicates. Notethat carbon emission is outside the transmission range of the SEM's Be window, so we cannot say anything about the presence or absence of carbon and hence carbonate or organic complexation from the SEM data alone.

A typical luminescencespectrum from these bright green emitters seen in the bulk SP2, SP9, A11, and A14 samples using defocused (i.e., wide-area) ultraviolet excitation is shown in Figure 5 . These spectra can be deconvoluted into two components, a structured component plus an underlying broad component. Therearethreedistinct lines of evidence demonstrating that this deconvolution reflects two chemically different species rather than just a spectral artifact. First, while the mathematical fit to an emission decay curve for most pure uranyl samples requires only onetimeconstant, thefit for the bright green emitters using wide-area excitation typically required at least two time constants for an adequate fit, suggesting that two or more species (with different excited state lifetimes) were contributing to theluminescence. Second, as described in more detail below, a subset of finely divided green luminescing particles (as opposed to thelarger grained, tabular particles) was found with spectral features similar to the underlying broad component of the deconvoluted spectra in Figure 5. Third, we were able to isolate a single quartz particle from an SP2 sample that had a noticeable coating of the bright green emissive species and gave a spectrum comparable to the composite spectrum shown in Figure 5. Following mild agitation of this particlein deionized water, thespectral intensity associated with the highly structured signal was greatly diminished but the broad underlying signal remained at approximately equal intensity to that seen in the 


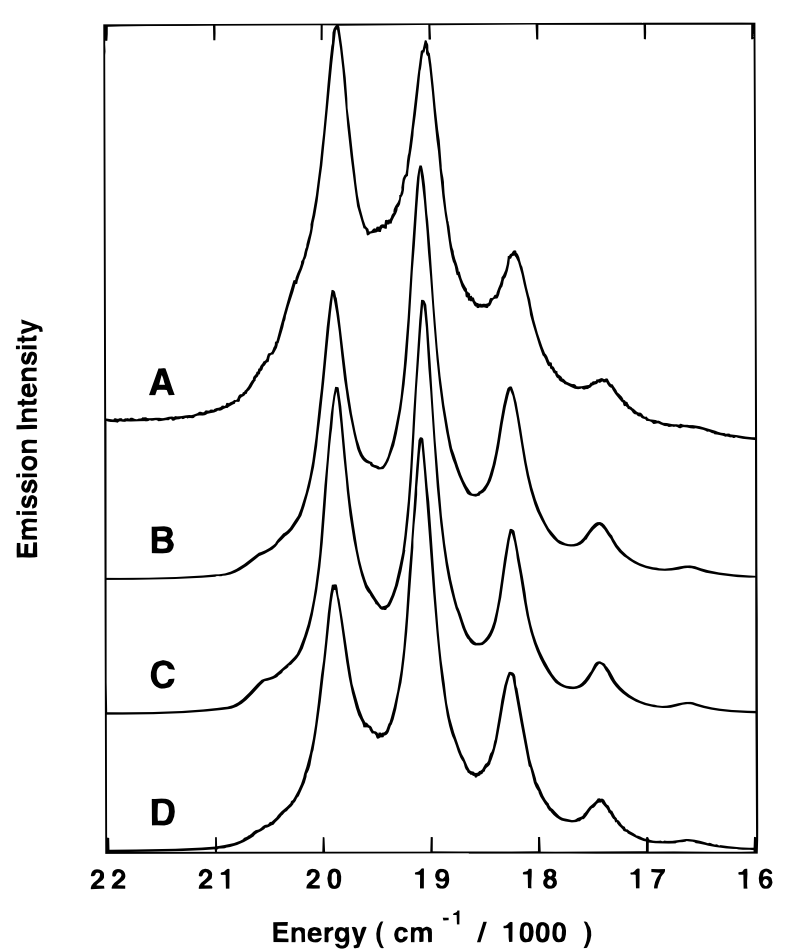

FIGURE 6. Comparison of the luminescence spectrum from isolated green emitters from sample lot SP2 (A) with those from three uranyl phosphate pure mineral phases (B is phosphuranylite, $C$ is metaankoleite, and $D$ is meta-autunite) obtained using $364-\mathrm{nm}$ argon-ion laser excitation. All three mineral specimens came from the Smithsonian collection. See Table 2 for the chemical formulas of the minerals.

unwashed particle. This demonstrates that two separate chemical components contributed to theoriginal spectrum.

From the library of emission spectra for uranyl minerals (23), it is possible to make some specific conclusions and assignments regarding the emissive phases found in the Fernald soils. First, it is unlikely that uranyl carbonates are the species responsible for the structured green emission seen in thesoil samples. This is becausethesimplest uranyl carbonate, rutherfordine $\left(\mathrm{UO}_{2} \mathrm{CO}_{3}\right)$, yields only broad, structureless emission, and ternary carbonatemineralssuch as liebigite (Table 2 ) while possessing structured emission have significantly shifted emission energies. For similar reasons, we can eliminate the common ternary uranyl hydroxide becquerelite. The structured emission spectra from theFernald soils arealso different from those of uranyl exchange and surface complexes on common clay minerals such as smectites and kaolinites $(9,10,24)$ and from uranyl nitrates. Similar structured emission spectra, however, are found for the uranyl silicate mineral sklodowskite and for thephosphateminerals meta-autunite, meta-ankoleite, and phosphuranylite. As noted above, the crystal habit of sklodowskite is not consistent with that found for thegreen emissive particles, nor is the lowest energy band in the emission spectrum quite the same as that seen in the spectrum from the soil species. Furthermore, while the three uranyl phosphate minerals have similar emission spectra (Figure 6), their Raman spectra in the region of the totally symmetric uranyl stretch and the phosphatestretches are very distinct. As shown in Figure 7, the Raman spectra from the structured green emitters in most soil samples have numerous bands that match extremely well only with those from meta-autunite. Therefore, the majority of the uranyl species giving rise to the structured green emission

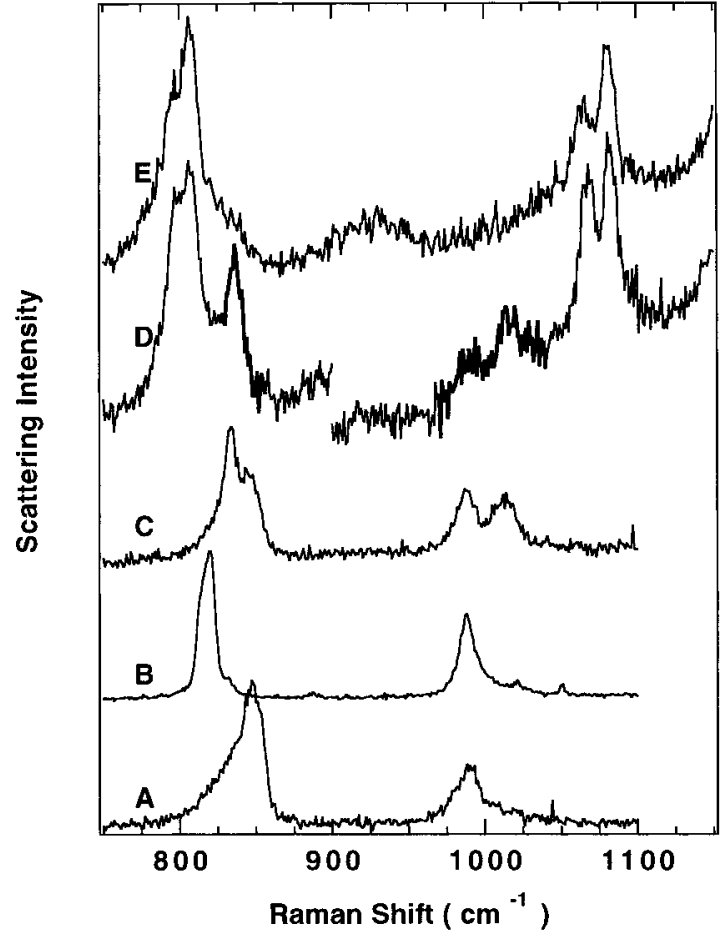

FIGURE 7. Raman spectra for pure uranyl mineral phases and uranium-contaminated Fernald soil samples obtained using pointfocused 364-nm excitation from an argon-ion laser: (A) phosphuranylite; (B) meta-ankoleite; (C) meta-autunite (All specimens from the Smithsonian collection. See Table 2 for the chemical formulas of these minerals.); (D) quartz particle isolated from sample lot SP2 containing a coating of bright green emissive uranyl phase; $(E)$ same particle as in $D$ following the removal of emissive uranyl phase. Additional peaks in $D$ and $E$ at $\sim 800$ and $\sim 1075 \mathrm{~cm}^{-1}$ are from the quartz substrate.

in bulk SP2, SP9, A11, and A14 samples are assigned as meta-autunite. However, we did not collect exhaustive Raman data on these structured green emitters and cannot, therefore, rule out the assignment of some of these to the other uranyl phosphate phases.

As for the species giving rise to the broad, underlying component in the bright green composite emission spectra (Figure 5), the spectra from these species are very similar in energy and band shapeto that from a naturally occurring, crystalline schoepite sample, which is distinct from those for freshly precipitated uranyl hydroxides (Figure 8). The uranyl carbonaterutherfordineisalso a broad-band emitter. However, the emission energy of rutherfordine (19 400 $\mathrm{cm}^{-1}$ ) is higher than the broad component of the green emitters $\left(18800 \mathrm{~cm}^{-1}\right)$, and the band shape shows no obvious structure. Furthermore, the presence of schoepite has been confirmed by XRD data from a hand-concentrated sample of the green emitting particulates. In addition, the finely dispersed green emitters found in SP9 samples produced broad spectral features similar to that of schoe pite, although the peak sometimes fell at lower energies than the more crystallineschoepite. These minor changes in the spectral features are attributed to schoepite in various stages of aging from freshly precipitated to dehydrated forms (21).

Orange emissive particles have been found in SP2, SP4, and SP9 samples, frequently in intimate contact with the structured green uranyl phosphate phase. There appear to be two distinct classes of orange emitters. The first, minor class (Figure 9A) is possibly associated with a 


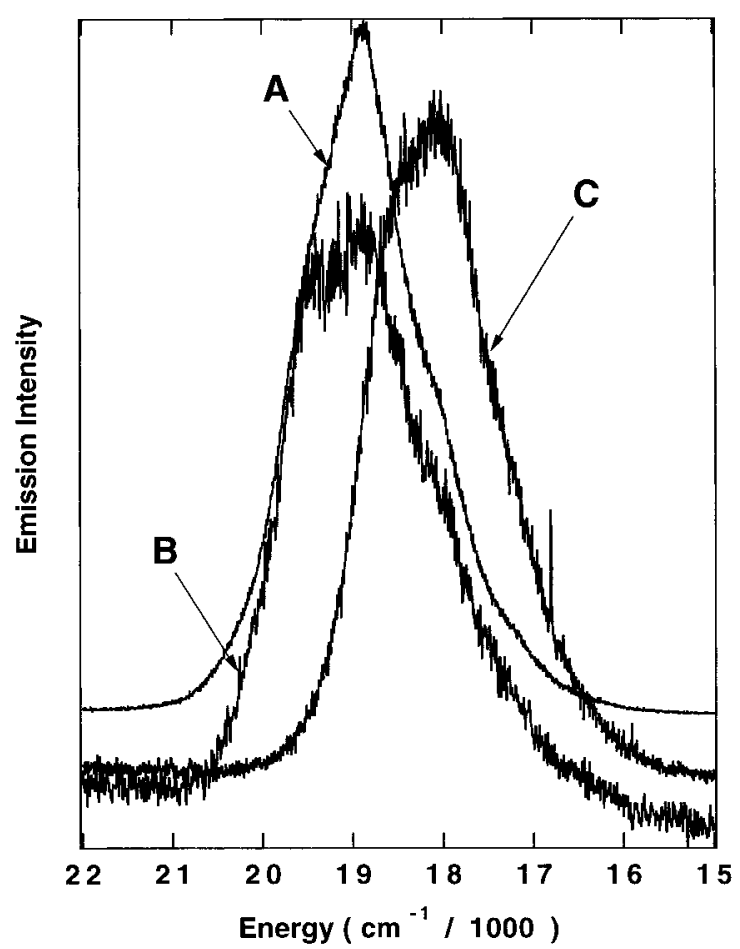

FIGURE 8. Luminescence spectra obtained from specimen uranyl hydroxide phases using 364-nm argon-ion excitation: (A) schoepite obtained from the University of New Mexico mineral collection; (B) schoepite obtained from the Smithsonian collection; (C) freshly precipitated uranyl hydroxide solid.

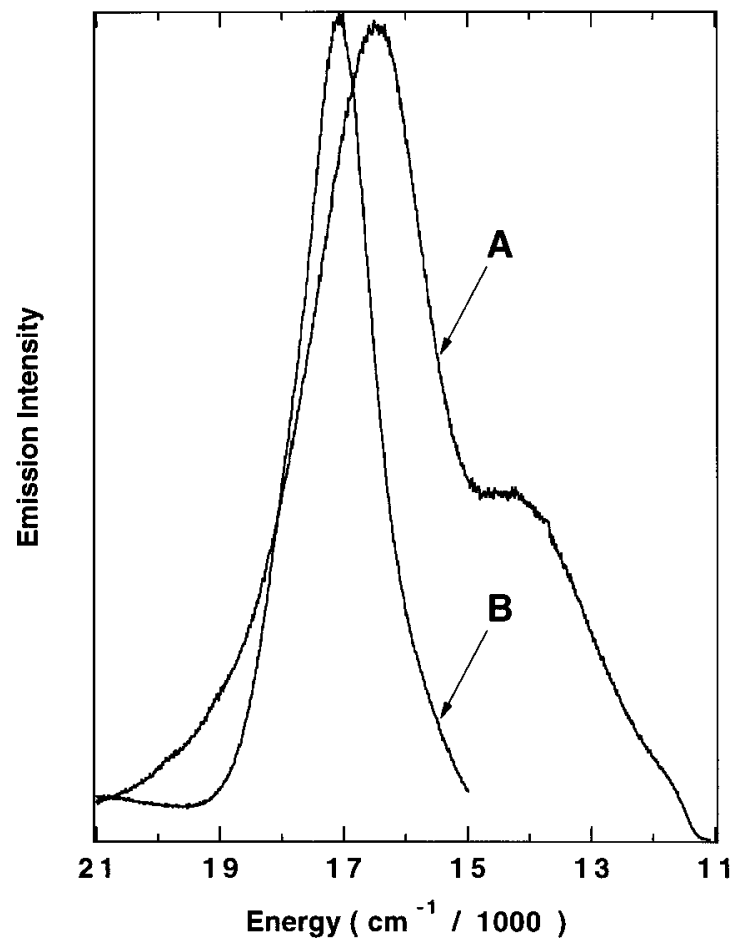

FIGURE 9. Luminescence spectra obtained from the particulate orange emissive uranyl phases in samples from lot SP2 (A) and lot B 16 (B) using 364-nm excitation from an argon-ion laser.

carbonate matrix (based on the appearance of carbonate bands in the Raman spectra) and is photochemically stable. This phase has an intense low energy shoulder in the emission profile. The second class does not have this shoulder and is photochemically very unstable with respect to UV excitation. This second class dominates the occurrence of orange emitters (Figure 9B). The photochemical instability ismanifest in a diminution in emission intensity over time for samples continuously illuminated with UV light. Furthermore, a comparison of optical micrographs of these orange emissive phases prior and subsequent to UVillumination shows significant changes in the color and morphology of these phases. Obtaining an exact identification of these orange emitters is problematic because the emission spectral band shapes vary from occurrence to occurrence and they do not yield Raman data because of the noted decomposition. Nonetheless, the photochemical instability is suggestive of uranyl species complexed by organic ligands (8a). The assignment of these species as uranyl-organic ligand complexes is supported by the lack of signatures from potential inorganic anions in theenergy dispersiveSEM spectrum, as described above. Moreover, the SP2 samples are among the samples that exhibit the orangeluminescence, and thesewerealso taken near the plant 2/3 area at thesite where the organic solvents and complexants associated with the PUREX process are known to have been spilled into the soil. These orange emissivephases could al so beuranyl complexes of naturally occurring organics such as humates, although such complexes might not be expected to form discrete particles.

Theoptical luminescenceand microphotographic results for the samples that underwent size and density fractionation are generally consistent with the data obtained for similar samples that did not undergo fractionation. In particular, the luminescence from hexavalent uranium species in these samples continues to be dominated by three types of phases; a uranyl phosphate phase (autunite, possibly some phosphuranyliteor meta-ankoleite), a uranyl hydroxide phase (most probably schoepite), and an illdefined uranyl organic phasehaving characteristic orange luminescence. Notably, the abundance of these emissive phases is decreased in the medium- and heavy-density fractions of all soils examined consistent with the observation based on XASoxidation-state distributions. However, the heavier density fractions do still contain some emissive $\mathrm{U}(\mathrm{VI})$ phases, demonstrating again that density fractionation is not completely effective in segregating $U(I V)$ and $\mathrm{U}(\mathrm{VI})$ phases.

Some variability in the spectral properties of the uranyl phosphate phase(s) and the uranyl hydroxide phase(s) is also apparent from the data on the size/ density fractions. These minor perturbations (e.g., line widths and lifetimes) are most probably associated with differing degrees of weathering of the same general phases. For example, differences in the waters of hydration and/ or the degree of crystallinity of the phase could account for the observed spectral differences. Unfortunately, we have insufficient data to determine if the extent of such weathering is correlated with the size and/or density of the substrate with which the uranium is associated.

The chemical identities of the contaminant uranium, especially of the green luminescing species, suggest that considerable weathering has occurred to produce these secondary uranium phases. Threemajor sourceterms have been identified (Table 1 ) that represent many potential different uranium species, many of them being zero valent and tetravalent. Nonetheless, $\sim 75-95 \%$ of the uranium in the samples we examined are in the hexavalent form, as expected from the ambient redox state of the soil. The presence of the iron(III) phase goethite requires that the oxidation state of uranium be the hexavalent form if equilibrium is being reached, as the $\mathrm{UO}_{2} / \mathrm{UO}_{2}{ }^{2+}$ oxidation 
potential is considerably lower than for the $\mathrm{Fe}(\mathrm{II}) / \mathrm{Fe}(\mathrm{III})$ couple (25). Furthermore, the presence of autunite and schoepite is exactly what has been found for the weathered zone of the oxidized natural analog sites of Koongarra, Australia (26), Pena Blanca, Chihuahua, Mexico (27), and the Katanga Province (Zaire) (28) and for alteration studies of uraninite $\left(\mathrm{UO}_{2}\right)$ from spent fuel $(29,30)$. In fact, the luminescence spectrum of the schoepite component of the bright green luminescing species indicates intermediate aging; we have found that freshly formed uranium oxyhydroxides have lower energy emission maxima than the aged form (Figure 8). This aging is correlated to the loss of structural waters from the solid (21). On the other hand, schoepite is not a long-term solubility-limiting phase for oxidized uranium in natural groundwaters, as other uranium minerals re-precipitate in the interstices of the collapsed unit cell as the hydrating waters are lost (21). The source of the phosphatefor theformation of autunite could be either trace amounts of apatite, decomposed organophosphates from the PUREX purification process, and/or anthropogenic phosphate from previous agricultural uses at this site. The $\mathrm{UO}_{2}$ analog studies (26-29) also found uranium silicates, which were not dominant in the Fernald soils. However, the silicates that did form in the analog studies at Koongarra formed in-situ, surrounding the weathering primary uranium source term, whereas the phosphates and oxyhydroxides were from a mobilized, reprecipitated uranium zone(26). Therefore, the prevalence of phosphate over silicates indicates the formation of secondary phases from the re-precipitation processes of solubilized hexavalent uranium. Other apparently minor or missing components are uranium carbonates (which could account for a minor amount of the orange emitting uranium particles) and uranium nitrate phases, especially considering the prevalence of calcite and dolomite in the soils and the use of nitric acid in the uranium reprocessing. Apparently, the differential solubility between theinsoluble phosphate minerals and more soluble carbonate or nitrate minerals (31) results in the observed prevalence of the phosphate phase(s). Finally, the release of cations in a weathering environment may help account for theapparent lack of association of the uranyl species with clay minerals, as these other cations, particularly $\mathrm{Ca}^{2+}$ and $\mathrm{Mg}^{2+}$, will compete effectively for the small amount of clay mineral cation-exchange sites.

With respectto targeting remediation technologies, these characterization data have the following implications: (1) Conventional soil-washing methods that are predicated on the selective and complete concentration of the contaminant in the fine (i.e., clay-size) fraction will not be effective for the Fernald soils. (2) Magnetic separation methods by themselves will not be very effective because of the abundance of hexavalent uranium species, many of which are not associated with paramagnetic phases. (3) The most effective approach is likely to be soil washing and/ or heap leaching using mild complexing agents such as carbonate solutions that attack the hexavalent uranium species. (4) Some near-term action is recommended given the predominance of thehexavalent speciation and the consequent greater potential of species in this oxidation stateto undergo surface and subsurface migration. The noted similarity in the uranyl speciation at the Fernald site relative to that found in the oxidized weathered zones at numerous natural analog sites suggests that one might anticipate a similar uranium speciation description at other sites having shallow subsurface uranium contamination. However, such generalizations are probably premature given the variabilities in climate, soil chemistry, and uranium sourceterm(s) that can be found in known uranium-contaminated sites throughout the world.

\section{Acknowledgments}

This work was supported by the U ranium in Soils Integrated Demonstration of theU.S. Department of Energy, Office of Environmental Restoration and Waste Management, Office of Technology Development. The authors express their gratitude to the Department of Earth and Planetary Sciences at the University of New M exico (Prof. R. C. Ewing and Dr. R. J. Finch) and the Smithsonian Institute for loans of reference minerals.

\section{Literature Cited}

(1) U.S. DOE. Remedial Investigation Report for Operable Unit 3. Task 6 Report, Feed Materials Production Center, Fernald, OH FMPC-0306-2; Department of Energy, Oak Ridge Operations Office: Oak Ridge, TN, 1990.

(2) Lee, S. Y.; Marsh, J. D. Characterization of uranium contaminated soils from DOE Fernald Environmental Management Project Site: Results of Phase I characterization; Oak Ridge National Laboratory: Oak Ridge, TN, 1992; Report ORNL/TM-11980.

(3) (a) Buck, E. C.; Cunnane, J. C.; Brown, N. R.; Dietz, N. L. Analytical Electron Microscopy Characterization of Uranium-Contaminated Soils from the Fernald Site: FY 1993 Report; Argonne National Laboratory: Argonne, IL, 1994; Report ANL-94/38. (b) Buck, E. C.; Brown, N. R.; Dietz, N. L. Mater. Res. Soc. Symp. Proc. 1994, 333, 437-444. (c) Buck, E. C.; Brown, N. R.; Dietz, N. L. Analytical Electron Microscopy Characterization of Fernald Soils: Annual Report October 1993-September 1994; Argonne National Laboratory: Argonne, IL, 1995; Report ANL-94/ 41.

(4) Koningsberger, D. C.; Prins, R. X-Ray Absorption: Principles, Applications, Techniques of EXAFS, SEXAFS, and XANES; John Wiley \& Sons: New York, 1988.

(5) Chisholm-Brause, C.; Conradson, S. D.; Buscher, C. T.; Eller, P. G.; Morris, D. E. Geochim. Cosmochim. Acta 1994, 58, 36253631.

(6) Bertsch, P. M.; Hunter, D. B.; Sutton, S. R.; Bajt, S.; Rivers, M. L. Environ. Sci. Technol. 1994, 28, 980-984.

(7) Chisholm-Brause, C. J.; Conradson, S. D.; Eller, P. G.; Morris, D. E. Mater. Res. Soc. Symp. Proc. 1992, 257, 315-322.

(8) (a) Rabinowitch, E.; Belford, R. L. Spectroscopy and Photochemistry of Uranyl Compounds; Pergamon Press: Oxford, 1964. (b) Weigel, F. Chemistry of the Actinides; Katz, J. J., Seaborg, G. T., Morss. L. R., Eds.; Chapman and Hall: London, 1986; Vol. 1, Chapter 5, pp 169-442.

(9) Chisholm-Brause, C. J.; Morris, D. E.; Richard, R. E. Water-Rock Interactions; Kharaka,Y. K., Maest, A. S., Eds.; A. A. Balkema Publishers: Rotterdam, 1992; Vol. 7, pp 137-140.

(10) Morris, D. E.; Chisholm-Brause, C. J.; Barr, M. E.; Conradson, S D.; Eller, P. G. Geochim. Cosmochim. Acta 1994, 58, 3613-3623.

(11) Long, D. A. Raman Spectroscopy; McGraw-Hill: London, 1977.

(12) Tait, C. D.; Conradson, S. D.; Donohoe, R. J.; Musgrave, J. A.; Hess, N. J.; Morris, D. E. Speciation of Uranium in Fernald Soils by Molecular Spectroscopic Methods: Characterization of Decontaminated Soils. To besubmitted to Environ. Sci. Technol.

(13) Cunnane, J. C.; Gill, V. R.; Lee, S.-Y.; Morris, D. E.; Nickelson, M D.; Perry, D. L.; Tidwell, V. C. Uranium Soils Integrated Demonstration: Soil Characterization Project Report; Fernald Environmental Management Project, Fernald Environmental Restoration Management Corp.: Cincinnati, OH, 1993; Report FEMP/SUB-058/UC-702.

(14) Kneff, D. W.; Oliver, B. M.; Subbaraman, G. Updated Homogeneity Evaluation of Fernald Soils Prepared for Treatability Studies; Rocketdyne Division, Rockwell International: 1993; Report ETEC/GEN-ZR-0018.

(15) Elless, M. P.; Lee, S.-Y. Physicochemical and mineralogical characterization of transuranic contaminated soils for uranium soil integrated demonstration; Oak Ridge National Laboratory: Oak Ridge, TN, 1994; Report ORNL/TM-12848.

(16) Musgrave, J. A.; Janecky, D. R.; Carey, R. G.; Tait, C. D. Rev. Sci. Instrum. 1994, 65, 1877-1882.

(17) (a) Mustre de Leon, J.; Rehr, J. J.; Zabinsky, S. I. Phys. Rev. B 1991, 44, 4146-4156. (b) Rehr, J. J.; Mustre de Leon, J.; Zabinsky, 
S. I.; Albers, R. C. J. Am. Chem. Soc. 1991, 113, 5135-5140. (c) Rehr, J. J.; Albers, R. C.; Zabinsky, S. I. Phys. Rev. Lett. 1992, 69, 3937-3400.

(18) Peters, G. G.; Hayes, J. M.; Hieftje, G. M. Chemical Separations and Measurements: Theory and Practice of Analytical Chemistry; W. B. Saunders: Philadelphia, 1974; Chapter 18.

(19) Regression analysis of these calibration data shows that the absolute uncertainties (90\% confidenceinterval) in theoxidation state distribution from an unknown sample with a single determination of the peak shift value range from 6\% at 50\% $\mathrm{U}(\mathrm{VI})$ (i.e., in the middle of the calibration curve) to $\sim 7 \%$ at $100 \% \cup(V I)$ (i.e., at the extrema of the calibration curve).

(20) Tri- and pentavalent uranium species are not expected to be stable in surface and shallow subsurface environments (ref 8b). No species in these oxidation states or any metallic uranium were observed in any characterization work here or in refs 3 and 6.

(21) Finch, R. J.; Miller, M. L.; Ewing, R. C. Radiochim. Acta 1992 58/59, 433-443.

(22) Roberts, W. L.; Campbell, T. J.; G. R. Rapp, J.; Wilson, W. E. Encyclopedia of Minerals, 2nd ed.; Van Nostrand Reinhold Publishers: New York, 1990.

(23) Morris, D. E.; Donohoe, R. J.; Tait, C. D.; Ewing, R. C.; Finch, R. J.; Chisholm-Brause, C. J.; Musgrave, J. A. Manuscript in preparation.

(24) Chisholm-Brause, C. J.; Morris, D. E. Unpublished results on kaolinite surface complexation.
(25) Thomson, J.; Higgs, N. C.; Croudace, I. W.; Colley, S.; Hydes, D. J. Geochim. Cosmochim. Acta 1993, 57, 579-595.

(26) Waite, T. D.; Payne, T. E. Metals in Groundwater; Allen, H. E., Perdue, E. M., Brown, D. S., Eds.; Lewis Publishers: Boca Raton, 1993; pp 349-410.

(27) Pearcy, E. C.; Prikryl, J. D.; Murphy, W. M.; Leslie, B. W. J. Appl. Geochem. 1994, 9, 713-732.

(28) Finch, R. J.; Ewing, R. C. Radiochim. Acta 1991, 52/53, 395-401.

(29) Johnson, L. H.; Shoesmith, D. W. In Radioactive Wasteforms for the Future; Lutze, W., Ewing, R. C., Eds.; Elsevier: New York, 1988; p 665.

(30) Wronkiewicz, D. J.; Bradley, C. R.; Bates, J. K. Geologic Society of America; Geologic Society of America: Boston, MA, 1993; pp T.36 IEE:Geologic Disposal of Nuclear Waste, Session 69.

(31) Sandino, A.; Bruno, J. Geochim. Cosmochim. Acta 1992, 56, 41354145.

(32) Fleischer, M.; Mandarino, J. A. Glossary of Mineral Species 1991; The Mineralogical Record, Inc.: Tucson, 1991.

Received for review October 6, 1995. Revised manuscript received March 22, 1996. Accepted March 25, $1996 .{ }^{\otimes}$

\section{ES950745I}

${ }^{\otimes}$ Abstract published in Advance ACS Abstracts, May 15, 1996. 